\title{
Anti-RSV prophylaxis efficacy for infants and young children with cystic fibrosis in Ireland
}

\author{
Barry Linnane ${ }^{1,2,3,4}$, Miranda G. Kiernan ${ }^{3}$, Nuala H. O'Connell ${ }^{3,5}$, Linda Kearse ${ }^{2,3}$ and Colum P. Dunne ${ }^{3 *}$
}

\begin{abstract}
Rationale: There is limited evidence supporting the routine use of palivizumab in paediatric cystic fibrosis (CF) patients to reduce respiratory syncytial virus (RSV) infection and related hospitalisation. Despite this, anti-RSV prophylaxis is increasingly common. This is the first report from Ireland regarding palivizumab outcomes for children with CF, under 2 years old, despite the greatest prevalence of CF globally.

Methods: An audit was performed at a tertiary hospital in Ireland's mid-West to document all children with $\mathrm{CF},<24$ months old, who received palivizumab over a five year period and comparision made with all eligible children for the prior five year period who had not received the product (also CF patients). Palivizumab was administered to both cohorts in their first year of life. Hospitalisation rates were compared using Fisher's exact test. Incidence of RSV and Pseudomonas aeruginosa infection was recorded.
\end{abstract}

Results: A total of 19 patients who received palivizumab were included in the study; comparision was made with a retrospective control group of 30 patients. Prophylactic palivizumab did not prevent hospitalisation for 10/19 patients, 3 of whom were affected by RSV. This was significantly greater than in the control group, where no hospitalisations were recorded $(p<0.0001)$. P. aeruginosa was isolated in one case from the study cohort, while no $P$. aeruginosa was detected in the control group.

Conclusions: This study, the first of its kind from Ireland where CF prevalence is highest, does not provide unequivocal support for prophylactic use of palivizumab in CF patients under 2 years. Despite being derived from a small sample size, based on these data and complementary clinical observation, we have discontinued such prophylaxis. However, should reported incidence of RSV-related hospitalisation increase, there is scientific plausibility for appropriately powered, randomised, controlled trials of palivizumab.

Keywords: Paediatric, Cystic fibrosis, RSV, Palivizumab, Efficacy

\section{Correspondence}

Dear Editor,

Respiratory syncytial virus (RSV) is the most commonly attributed cause of lower respiratory tract infections in young infants [1]. As RSV is recognised as affecting almost $100 \%$ of children by 24 months, the use of anti-RSV prophylaxis, in the form of humanised monoclonal antibody palivizumab, has become ubiquitous due to its safety and efficacy profile, especially in the context of preventing hospitalisation of high-risk children, such as those born pre-maturely $[1,2]$. Globally, Ireland has the highest prevalence of cystic fibrosis (CF) (2.98 per 10,000 population)

\footnotetext{
* Correspondence: colum.dunne@ul.ie

${ }^{3}$ Graduate Entry Medical School and Centre for Interventions in Infection, Inflammation \& Immunity (4i), University of Limerick, Limerick, Ireland Full list of author information is available at the end of the article
}

[3], a condition associated with increased susceptibility to both bacterial and viral respiratory infection. Despite this, there is no previous report of palivizumab's prophylactic efficacy in a cohort of Irish CF patient under 24 months.

In the context of paediatric patients, such as those with CF at risk of RSV-related hospitalization, there has been considerable expert discussion regarding effectiveness of palivizumab use, which can be summarized as consensus that insufficient data exist to concretely support the economics, safety and tolerability of its use in this setting [4-6]. Of the extant studies, respondents to a United Kingdom-based survey would prescribe palivizumab if funding were not an issue [7] and, although a large number of CF physicians in North America have prescribed palivizumab to CF infants in their first year of 
life, only half consider this to be standard care [8]. RSV has been identified as a main cause of hospitalisation in cystic fibrosis (CF) infants, however, hospitalisation was most commonly associated with concomitant bacterial infection and the most severe symptoms of lower airway inflammation were seen in those patients co-infected with RSV and Pseudomonas aeruginosa [9]. Indeed, RSV has been proven to enhance $P$. aeruginosa infection of respiratory epithelial cells, suggesting a role for viral-bacterial interactions in exacerbations of CF lung disease [10]. To the best of our knowledge, only one study has reported the effects of palivizumab on $P$. aeruginosa colonization, with a lack of demonstrable efficacy over placebo [11].

Here, with ethical approval, we performed an audit at University Hospital Limerick (Ireland), a tertiary referral centre, to document all children with CF, $<24$ months old, who received palivizumab during their first year of life (once a month for up to 7 months), over a 5 -year period. We compared the data with those of all eligible children with cystic fibrosis for the prior 5 year period who had not received the product. In both cohorts, assessment included: respiratory related hospitalisation; differential diagnosis; nasopharyngeal aspirate; and (due to the association between palivizumab and subsequent Pseudomonas infection) colonisation of the lower airways by $P$. aeruginosa at initiation of palivizumab prophylaxis or in the subsequent 12 months. Data are presented as mean \pm standard error. Fisher's exact test was used to compare hospitalisation rates of both groups.

In summary, 19 patients received palivizumab (mean doses: $5.2 \pm 0.37$ ) and met the criteria for inclusion in the study group, while $30 \mathrm{CF}$ infants who attended UHL from 2004 to 2009 , did not receive palivizumab and constituted the control group. Ten patients (53\%) who received prophylactic palivizumab were hospitalised (mean age at admission: $3.1 \pm 0.98$ months), with 3 of those cases confirmed using molecular techniques as relating to RSV. Mean age at time of first palivizumab treatment was $5.5 \pm 0.74$ months. P. aeruginosa was isolated from one of those children the following year. No children from the control group were hospitalised $(p<0.0001)$, and no $P$. aeruginosa detected.

These results complement previous reports of prophylactic anti-RSV strategies for children, but add considerably to existing knowledge in detailing outcomes from a geographic region in which prophylaxis could have been especially valuable for paediatric CF patients had a benefit been evident. We observed a low rate of RSV-related hospitalisations overall, in addition to a small sample size, similar to elsewhere, that impaired ability to draw statistically relevant conclusions. However, due to economic constraints and the lack of supportive clinical evidence, palivizumab prophylaxis was discontinued. Our study was limited by not assessing the impact of palivizumab intervention in RSV season only and, furthermore, our results do not address other aspects of palivizumab use or potential benefit, including: its role in infants diagnosed with CF by newborn screening; the possibility that changes to timing of palivizumab administration (when to begin and duration of spacing) may improve performance; similarly, whether increased dosage could enhance outcomes; use therapeutically; emergence of resistance; or variation of antigenic presentation affecting efficacy. However, previous reports on the use of palivizumab in RSVhospitalisations have demonstrated positive effects [12-14]. Therefore, in summary, we believe that, should reported incidence of RSV-related hospitalisation increase, there is scientific plausibility for appropriately powered, randomised, controlled trials of palivizumab.

\section{Competing interest}

The authors declare that they have no competing interests.

\section{Authors' contributions}

Dr BL conceived the study and conducted the data collection. Ms MK performed data analysis and contributed to the manuscript. Dr N O'C conducted data collection, and contributed to critical revision of the manuscript. Ms LK performed data analysis and contributed to the manuscript. Prof CD drafted the manuscript and takes responsibility for the overall content as guarantor. All authors read and approved the final manuscript.

\section{Acknowledgements}

The authors thank the staff of the UHL microbiology lab for their assistance with this study. The authors $(C D, B L$ and $L K)$ have received funding from the National Children's Research Centre, Crumlin, Dublin, Ireland and the University of Limerick's Graduate Entry Medical School Strategic Research Fund.

\section{Author details}

${ }^{1}$ Cystic Fibrosis Unit, University Hospital, Limerick, Ireland. ${ }^{2}$ National Children's Research Centre, Crumlin, Dublin, Ireland. ${ }^{3}$ Graduate Entry Medical School and Centre for Interventions in Infection, Inflammation \& Immunity (4i), University of Limerick, Limerick, Ireland. ${ }^{4}$ Study of Host Immunity and Early Lung Disease in CF (SHIELD CF), Dublin, Ireland. ${ }^{5}$ Department of Clinical Microbiology, University Hospital Limerick, Limerick, Ireland.

Received: 27 July 2015 Accepted: 31 August 2015

Published online: 15 October 2015

\section{References}

1. Rodriguez R, Ramilo O. Respiratory syncytial virus: how, why and what to do. J Infect. 2014;68 Suppl 1:S115-8. doi:10.1016/j.jinf.2013.09.021.

2. Wegzyn C, Toh LK, Notario G, Biguenet S, Unnebrink K, Park C, et al. Safety and effectiveness of palivizumab in children at high risk of serious disease due to respiratory syncytial virus infection: a systematic review. Infect Dis Ther. 2014;3(2):133-58. doi:10.1007/s40121-014-0046-6.

3. Farrell PM. The prevalence of cystic fibrosis in the European Union. J Cyst Fibros. 2008;7(5):450-3. http://dx.doi.org/10.1016/j.jcf.2008.03.007.

4. Robinson KA, Odelola OA, Saldanha IJ. Palivizumab for prophylaxis against respiratory syncytial virus infection in children with cystic fibrosis. Cochrane Database Syst Rev. 2014;5, CD007743. doi:10.1002/14651858.CD007743.pub5.

5. Gaboli M, de la Cruz OA, de Aguero MI, Moreno-Galdo A, Perez GP, de Querol MS. Use of palivizumab in infants and young children with severe respiratory disease: a Delphi study. Pediatr Pulmonol. 2014;49(5):490-502. doi:10.1002/ppul.22826.

6. Thomas G. A cost-benefit analysis of the immunisation of children against respiratory syncytial virus (RSV) using the English Hospital Episode Statistics (HES) data set. Eur J Health Econ. 2015. doi:10.1007/s10198-014-0662-9.

7. McCormick J, Southern KW. A survey of palivizumab for infants with cystic fibrosis in the UK. Arch Dis Child. 2007;92(1):87-8. doi:10.1136/adc.2006.0105338.

8. Giusti R. North American synagis prophylaxis survey. Pediatr Pulmonol. 2009;44(1):96-8. doi:10.1002/ppul.20922. 
9. Armstrong D, Grimwood K, Carlin JB, Carzino R, Hull J, Olinsky A, et al. Severe viral respiratory infections in infants with cystic fibrosis. Pediatr Pulmonol. 1998;26(6):371-9.

10. Van Ewijk BE, Wolfs TF, Aerts PC, Van Kessel KP, Fleer A, Kimpen JL, et al. RSV mediates Pseudomonas aeruginosa binding to cystic fibrosis and normal epithelial cells. Pediatr Res. 2007;61(4):398-403. doi:10.1203/ pdr.0b013e3180332d1c.

11. Cohen A, Boron M, Dingivan C. A phase IV study of the safety of Synagis (palivizumab) for prophylaxis of respiratory syncytial virus disease in children with cystic fibrosis [abstract]. American Thoracic Society Abstracts; International Conference; 20052005. p. p.A178.

12. Sanchez-Solis M, Gartner S, Bosch-Gimenez V, Garcia-Marcos L. Is palivizumab effective as a prophylaxis of respiratory syncytial virus infections in cystic fibrosis patients? A meta-analysis. Allergol Immunopathol (Madr). 2015;43(3):298-303. doi:10.1016/j.aller.2013.09.003.

13. Speer ME, Fernandes CJ, Boron M, Groothuis JR. Use of Palivizumab for prevention of hospitalization as a result of respiratory syncytial virus in infants with cystic fibrosis. Pediatr Infect Dis J. 2008;27(6):559-61. doi:10.1097/NF.0b013e3181673c15.

14. Giebels K, Marcotte JE, Podoba J, Rousseau C, Denis MH, Fauvel V, et al. Prophylaxis against respiratory syncytial virus in young children with cystic fibrosis. Pediatr Pulmonol. 2008;43(2):169-74. doi:10.1002/ppul.20751.

\section{Submit your next manuscript to BioMed Central and take full advantage of:}

- Convenient online submission

- Thorough peer review

- No space constraints or color figure charges

- Immediate publication on acceptance

- Inclusion in PubMed, CAS, Scopus and Google Scholar

- Research which is freely available for redistribution 